\title{
The prognostic value of C-reactive protein/albumin ratio in human malignancies: an updated meta- analysis
}

\author{
Hong-jun $\mathrm{Xu}$ \\ Yan Ma \\ Fang Deng \\ Wen-bo Ju \\ Xin-yi Sun \\ Hua Wang
}

Department of Gastroenterology, Affiliated Hospital of Beihua

University, Jilin, Jilin province, China
This article was published in the following Dove Press journal:

OncoTargets and Therapy

19 June 2017

Number of times this article has been viewed

Purpose: This study aims to investigate the prognostic value of pretreatment C-reactive protein/ albumin ratio (CAR) in human malignancies by an updated meta-analysis.

Methods: PubMed, Web of Science, Cochrane Library and Wanfang databases were searched. Pooled hazard ratios (HRs) and odds ratios (ORs) with their corresponding 95\% confidence intervals (CIs) were used as effective values.

Results: A total of 25 studies with 12,097 patients were included in this meta-analysis. Pooled results showed that high pretreatment CAR was associated with poor overall survival (OS) (HR $=1.99,95 \% \mathrm{CI}: 1.65-2.40, P=0.000)$ and poor disease-free survival $(\mathrm{HR}=1.55,95 \% \mathrm{CI}$ : $1.34-1.79, P=0.000)$. In addition, high pretreatment $C A R$ was associated with increased 5-year mortality $(\mathrm{OR}=2.74,95 \% \mathrm{CI}: 2.11-3.55, P=0.000)$. Moreover, subgroup analysis demonstrated that high CAR was associated with poor OS despite variations in publication year, country, sample size, CAR cut-off value and treatment. However, high CAR was associated with poor OS in human malignancies except colorectal cancer ( $\mathrm{HR}=1.64,95 \% \mathrm{CI}$ : 0.96-2.80, $P=0.069$ ).

Conclusion: High pretreatment CAR indicates poor prognosis in human malignancies except colorectal cancer. Thus, pretreatment CAR serves as a prognostic marker in human malignancies and could be used in the evaluation of prognosis in clinical work.

Keywords: human malignancies, C-reactive protein/albumin ratio, prognosis, meta-analysis

\section{Introduction}

Human malignancy remains a public health problem worldwide, and is reported to be the second leading cause of death in the US. ${ }^{1}$ Based on GLOBOCAN estimates, 14.1 million new cancer cases and 8.2 million deaths occurred in 2012 worldwide, and the burden is projected to grow worldwide due to the growth and aging of the population. ${ }^{2}$ With the advance in early detection and treatment modality, the number of cancer survivors has increased steadily. ${ }^{3}$ However, many challenges remain unsolved, such as identifying economical and practical markers for prognosis.

It is reported that the response of the body to cancer is not a unique mechanism but has many parallels with inflammation and wound healing, during which inflammatory cells and cytokines in tumors are more likely to contribute to tumor growth, progression and immunosuppression. ${ }^{4}$ In clinical work, the commonly used inflammation markers include C-reactive protein (CRP), neutrophil, lymphocyte, platelet, D-dimer, fibrinogen, procalcitonin, and so on. Coincidentally, many inflammation-based scores, including Glasgow Prognostic Score, modified Glasgow Prognostic Score, neutrophilto-lymphocyte ratio, platelet-to-lymphocyte ratio and lymphocyte-to-monocyte ratio, have been reported to be associated with the prognosis of human malignancies. ${ }^{5-7}$
Correspondence: Hua Wang Affiliated Hospital of Beihua University, Jie Fang Middle Street No 12, Jilin I320I I, Jilin province, China $\mathrm{Tel}+86$ I39 044I 7013

Email wanghuabeihua@sina.com 
Recently, numerous publications have tried to explore the correlation of pretreatment C-reactive protein/albumin ratio (CAR) with the prognosis of human malignancies, including one published meta-analysis based on only 10 available studies. $^{8}$

However, the prognostic role of pretreatment CAR in human malignancies remains inconclusive. Therefore, to clarify this issue, we performed this updated meta-analysis based on more available studies.

\section{Methods}

\section{Search strategy}

A comprehensive search of PubMed, Web of Science, Cochrane Library and Wanfang databases was performed up to March 13th 2017. The following keywords were used: ("C-reactive protein/Albumin ratio" or "C-reactive protein Albumin ratio" or "CRP/Alb ratio") and ("Prognosis" or "Prognostic" or "recurrence" or "overall survival"). The detailed search strategy used in PubMed was as follows: “((((prognostic[Title/Abstract]) OR prognosis[Title/ Abstract]) OR overall survival[Title/Abstract]) OR recurrence[Title/Abstract]) AND ((C-Reactive Protein[Title/ Abstract]) AND albumin[Title/Abstract])". During this process, we also screened the references list of retrieved articles manually, in order to gain more potential eligible studies.

\section{Selection and exclusion criteria}

Studies were included if they met all the following criteria: (1) investigating the prognostic role of CAR in human primary malignancies; (2) CAR was obtained before any treatment; (3) survival outcomes including overall survival (OS) or/and disease-free survival (DFS) were included; and (4) relative hazard ratios (HRs) with their corresponding $95 \%$ confidence intervals (CIs) were available or could be calculated according to the provided survival data or KaplanMeier curve.

Studies were excluded if they met any of the following criteria: (1) studies were reviews, letters, case reports and duplicates; (2) studies did not include any survival outcomes; (3) HRs with corresponding 95\% CIs were not available or could not be calculated as mentioned. If multiple publications were based on the same origin of population, only the most informative or most recent one was enrolled.

\section{Data extraction}

Two investigators performed data extraction independently, during which discrepancies were solved by a consensus in this research team. The survival outcomes including OS, DFS and 5-year mortality were our main concerns. In addition, we extracted other relative basic information, including first author, publication year, country, cancer stage, cancer type, cut-off value for CAR, major treatment, data source and follow-up time. If results for both multivariate and univariate analyses were available, those for the former ones were extracted and used in the meta-analysis. When HRs with their 95\% CIs were unavailable, the total number of events (including observed deaths, cancer-specific death and cancer recurrences) and the sample numbers of each group were extracted to calculate HRs. ${ }^{9}$ In case neither crude HRs nor outcome data were available, Engauge Digitizer version 4.1 (http://sourceforge.net) was used to read the Kaplan-Meier curves, and then relative HRs with their 95\% CIs were calculated using the methods described by Tierney et al. ${ }^{9}$

\section{Statistical analysis}

In this meta-analysis, the pooled HRs and odds ratios (ORs) of included studies were calculated using STATA 10.0. Pooled HRs with corresponding 95\% CIs were used to assess the effect of CAR on OS and DFS, and pooled ORs with corresponding 95\% CIs were used to assess the effect of CAR on 5-year mortality. A combined HR or OR $>1$ indicated poor prognosis for patients with a high pretreatment CAR; otherwise, high pretreatment CAR served as a marker of good prognosis. Cochrane $Q$ test and $I^{2}$ statistic were used to test the potential heterogeneity across studies. ${ }^{10}$ If heterogeneity was significant $\left(I^{2}>50 \%\right.$ or/and $\left.P<0.1\right)$, we used a randomeffect model; otherwise, a fixed-effect model was used. Both Begg's test and Egger's test were used to evaluate the potential publication bias. ${ }^{11,12}$ All $P$-values were two-sided, and statistical significance was defined as $P<0.05$.

\section{Results}

\section{Literature search information}

Initially, 1,021 studies were identified through systematic research in available databases. Next, 992 studies were excluded after reading title and abstract: including reviews, duplicates, letters and articles without survival outcomes. Finally, 25 studies (24 in English and 1 in Chinese) $)^{13-37}$ were included in this meta-analysis after excluding 4 studies (3 studies with survival outcomes unavailable, 1 study based on metastasizing tumor rather than primary cancer) (Figure 1).

\section{Characteristics of included studies}

The characteristics of included studies are presented in Table 1. A total of 25 studies with 12,097 patients were included in this meta-analysis. The publication time ranged 


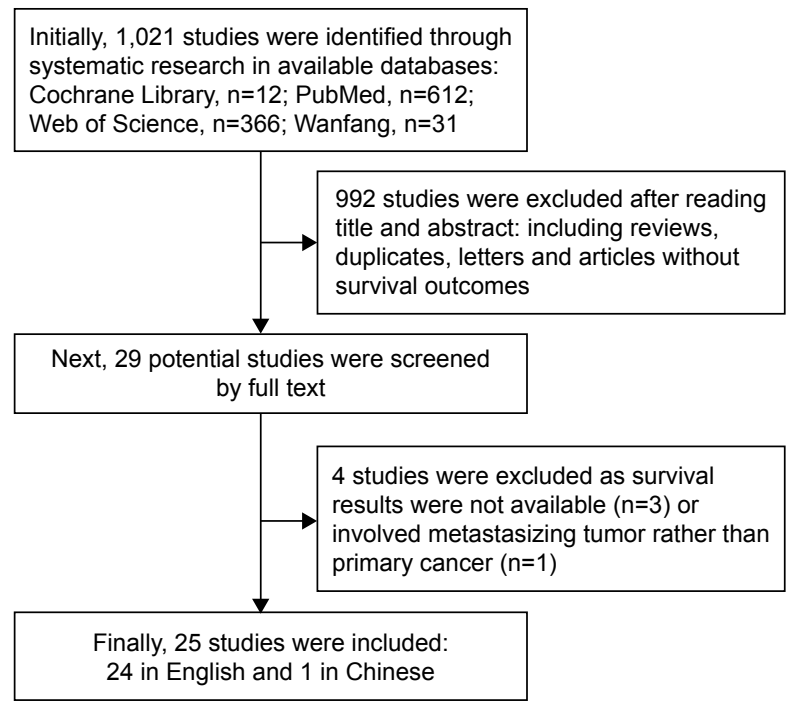

Figure I Flow diagram of searching relevant studies for this meta-analysis.

from 2014 to 2017, and all the studies were conducted in Asia (15 in China, 8 in Japan and 2 in Korea). The study sample sizes ranged from 40 to 2,685, with the median size of 386 . The cut-off values for high pretreatment CAR ranged from 0.028 to 0.54 , with the median cut-off value of 0.095 . As shown in the table, this meta-analysis was based on multiple cancer sites (oral cavity in 1, larynx in 1, nasopharynx in 4, esophagus in 2, lung in 3 , liver in 2, stomach in 2 , pancreas in 4 , colorectum in 4 and kidney in 2). The treatment methods were diverse, including surgical resection, chemotherapy, radiotherapy and multidisciplinary treatments. Among the 25 studies, all provided OS results, 8 provided DFS results and 7 provided 5-year mortality results.

\section{Meta-analysis results for OS}

In total, 25 studies involving 12,097 patients investigated the prognostic role of pretreatment CAR in OS. Since heterogeneity was significant across studies $\left(I^{2}=86.9 \%, P=0.000\right)$, a random-effect model was used. Pooled results demonstrated that high pretreatment CAR was associated with poor OS (HR $=1.99,95 \% \mathrm{CI}: 1.65-2.40, P=0.000)$, suggesting that patients with a high pretreatment CAR suffered from decreased OS rate (Figure 2).

\section{Meta-analysis results for DFS}

A total of 8 studies involving 4,226 patients reported the prognostic role of pretreatment CAR in DFS. The heterogeneity was not significant $\left(I^{2}=45.7 \%, P=0.075\right)$; therefore, a fixed-effect model was used. Combined results showed that high pretreatment CAR was associated with poor DFS $(\mathrm{HR}=1.55,95 \% \mathrm{CI}: 1.34-1.79, P=0.000)$, suggesting that patients with a high pretreatment CAR suffered from high tumor recurrence rate (Figure 3 ).

\section{Meta-analysis results for 5-year mortality rate}

Totally, 5 studies with 5,551 patients assessed the prognostic effect of high pretreatment CAR on 5-year mortality. The pooled results showed that high pretreatment CAR was associated with high 5-year mortality $(\mathrm{OR}=2.74,95 \% \mathrm{CI}$ : 2.11-3.55, $P=0.000$, random-effect model), which also meant that patients with a high pretreatment CAR suffered from decreased survival rate (Figure 4).

\section{Subgroup analysis}

Subgroup analysis showed that high pretreatment CAR was associated with poor OS despite variations in publication year, country, sample size, cut-off value for CAR and treatment (Table 2). However, when subgroup analysis was conducted according to cancer sites, the results showed that high pretreatment CAR was associated with poor OS in nasopharyngeal cancer $(\mathrm{HR}=1.56,95 \% \mathrm{CI}: 1.25-1.94, P=0.000)$, esophageal cancer $(\mathrm{HR}=1.84,95 \% \mathrm{CI}: 1.06-3.20, P=0.030)$, lung cancer $(\mathrm{HR}=1.63,95 \% \mathrm{CI}: 1.24-2.15, P=0.046)$, gastric cancer $(\mathrm{HR}=1.73,95 \% \mathrm{CI}: 1.31-2.28, P=0.000)$, hepatic carcinoma $(\mathrm{HR}=2.73,95 \% \mathrm{CI}: 2.07-3.60, P=0.000)$, pancreatic cancer $(\mathrm{HR}=2.25,95 \% \mathrm{CI}: 1.52-3.34, P=0.000)$, kidney cancer $(\mathrm{HR}=2.69,95 \% \mathrm{CI}: 1.54-4.69, P=0.000)$ and other cancers (including oral cancer and laryngeal cancer) (HR $=3.22$, 95\% CI: $1.18-8.80, P=0.022)$, but not colorectal cancer $(\mathrm{HR}=1.64,95 \% \mathrm{CI}: 0.96-2.80, P=0.069)$ (Figure 5). In addition, the HR for OS increased when the cut-off value of CAR increased, which could also be seen in Figure 2. Therefore, high pretreatment CAR is significantly associated with poor OS despite potential confounding factors.

\section{Publication bias}

In this meta-analysis, both Begg's test and Egger's test were used to check the potential publication bias. No publication bias was found in the meta-analysis with OS $(P=0.315)$ or 5-year mortality ( $P=0.764)$ when tested by Begg's test. However, publication bias was found in the meta-analysis with OS $(P=0.000)$ and 5-year mortality $(P=0.024)$ when tested by Egger's test, and DFS when tested by Begg's test $(P=0.035)$ as well as Egger's test $(P=0.006)$.

\section{Sensitivity analysis}

Since heterogeneity was found in the meta-analysis with OS, sensitivity analysis was performed for studies included in 


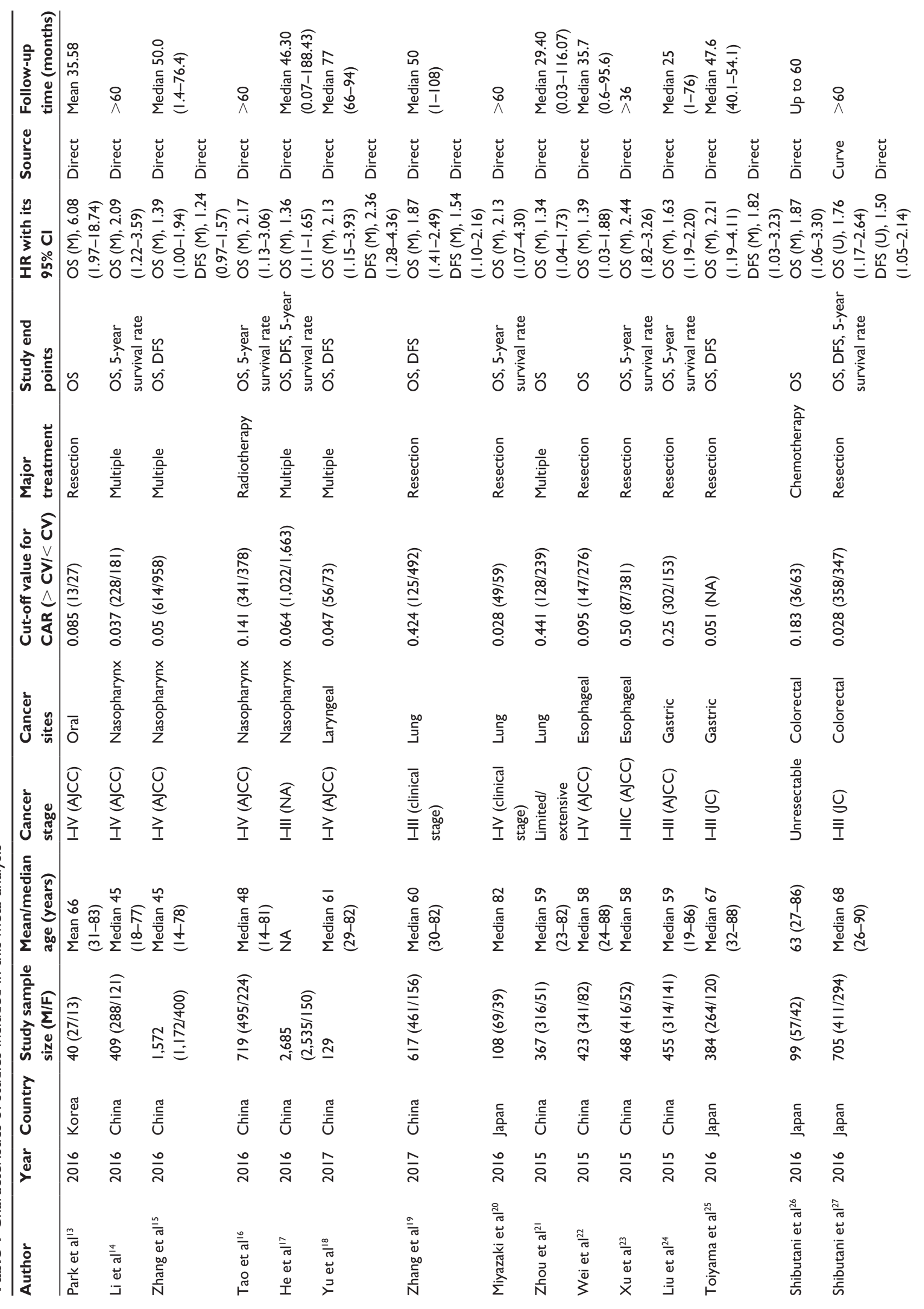




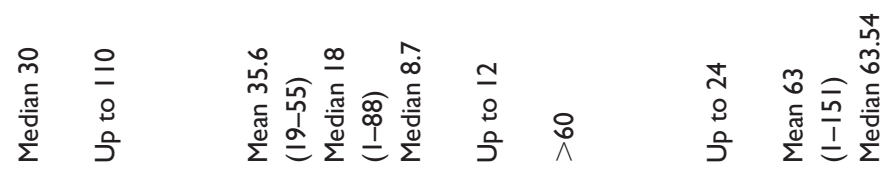

芯芯芯

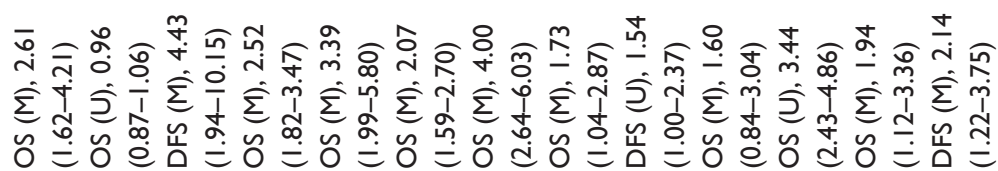

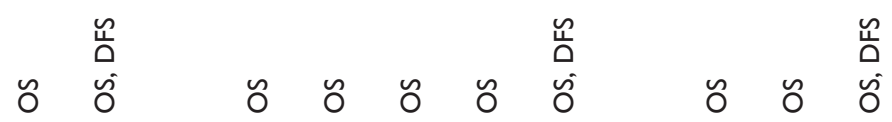

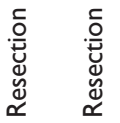

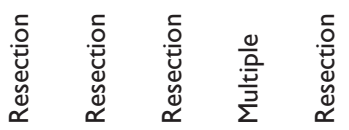

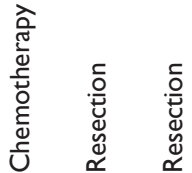

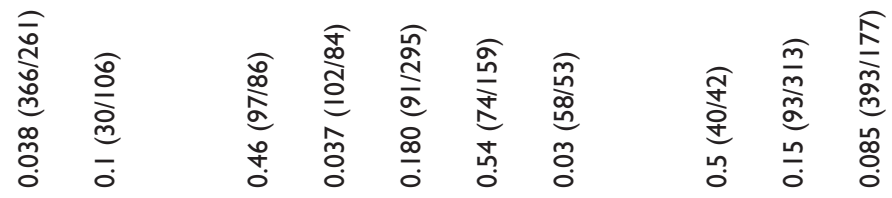

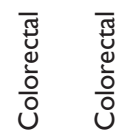

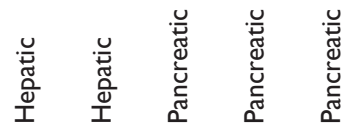

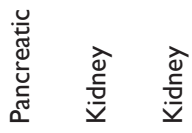

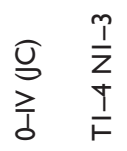

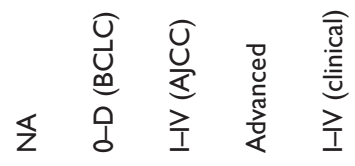

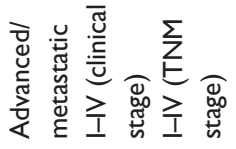

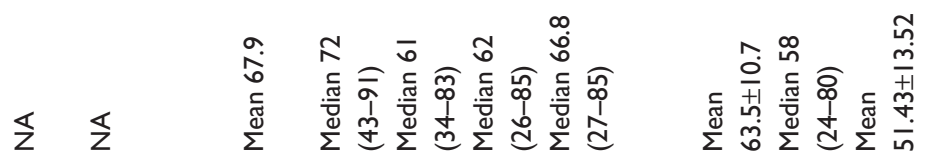

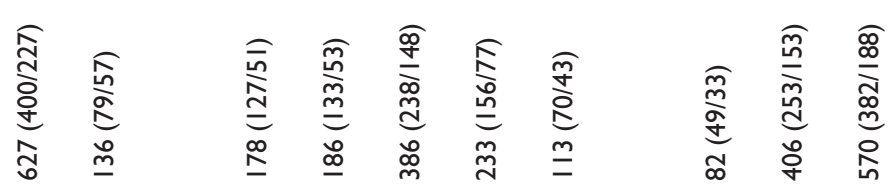

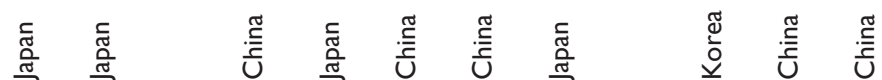

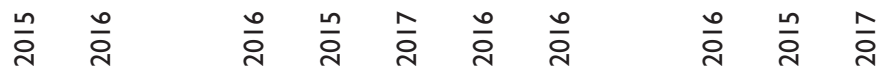

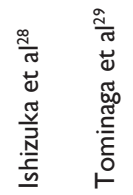

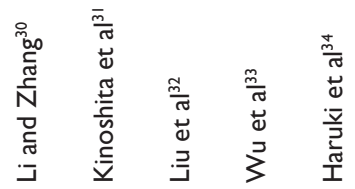

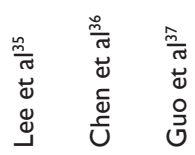




\begin{tabular}{|c|c|c|}
\hline Study ID & $\mathrm{HR}(95 \% \mathrm{Cl})$ & $\%$ weight \\
\hline \multicolumn{3}{|l|}{ Cut-off value $\leq 0.095$} \\
\hline Shibutani et $\mathrm{al}^{26,27}$ & $1.76(1.17,2.64)$ & 4.17 \\
\hline Ishizuka et $\mathrm{al}^{28}$ & $2.61(1.62,4.21)$ & 3.88 \\
\hline Wei et $\mathrm{al}^{22}$ & $1.39(1.03,1.88)$ & 4.57 \\
\hline Toiyama et al ${ }^{25}$ & $2.21(1.19,4.11)$ & 3.31 \\
\hline Kinoshita et $a^{31}$ & $3.39(1.99,5.80)$ & 3.65 \\
\hline Guo et $\mathrm{al}^{37}$ & $1.94(1.12,3.36)$ & 3.59 \\
\hline Yu et $\mathrm{al}^{18}$ & $2.13(1.15,3.93)$ & 3.33 \\
\hline Miyazaki et al20 & $2.13(1.07,4.30)$ & 3.03 \\
\hline He et $\mathrm{al}^{17}$ & $1.36(1.11,1.65)$ & 4.90 \\
\hline Zhang et al ${ }^{15}$ & $1.39(1.00,1.94)$ & 4.46 \\
\hline Li et $\mathrm{al}^{14}$ & $2.09(1.22,3.59)$ & 3.63 \\
\hline Park et al ${ }^{13}$ & $6.08(1.97,18.74)$ & 1.81 \\
\hline Haruki et al ${ }^{34}$ & $1.73(1.04,2.87)$ & 3.76 \\
\hline Subtotal $\left(I^{2}=51.5 \%, P=0.016\right)$ & $1.88(1.57,2.25)$ & 48.09 \\
\hline \multicolumn{3}{|l|}{ Cut-off value $>0.095$} \\
\hline Shibutani et $a^{27}$ & $1.87(1.06,3.30)$ & 3.52 \\
\hline Tominaga et $\mathrm{al}^{29}$ & $0.96(0.87,1.06)$ & 5.11 \\
\hline Xu et $\mathrm{al}^{23}$ & $2.44(1.82,3.26)$ & 4.61 \\
\hline Liu et $\mathrm{al}^{24}$ & $1.63(1.19,2.20)$ & 4.55 \\
\hline Li and Zhang ${ }^{30}$ & $2.52(1.82,3.47)$ & 4.50 \\
\hline Chen et $\mathrm{al}^{36}$ & $3.44(2.43,4.86)$ & 4.41 \\
\hline Zhou et $\mathrm{al}^{21}$ & $1.34(1.04,1.73)$ & 4.73 \\
\hline Zhang et al $^{19}$ & $1.87(1.41,2.49)$ & 4.63 \\
\hline Tao et $\mathrm{al}^{16}$ & $2.17(1.13,3.06)$ & 3.80 \\
\hline Wu et $\mathrm{al}^{33}$ & $4.00(2.64,6.03)$ & 4.14 \\
\hline Lee et $\mathrm{al}^{35}$ & $1.60(0.84,3.04)$ & 3.22 \\
\hline Liu et $\mathrm{al}^{32}$ & $2.07(1.59,2.70)$ & 4.70 \\
\hline Subtotal $\left(I^{2}=92.7 \%, P=0.000\right)$ & $2.00(1.47,2.72)$ & 51.91 \\
\hline Overall $\left(I^{2}=86.9 \%, P=0.000\right)$ & $1.99(1.65,2.40)$ & 100 \\
\hline$\frac{1}{0.0534}$ & & \\
\hline
\end{tabular}

Figure 2 Forest plots for the prognostic impact of CAR on overall survival in human malignancies. Studies were grouped by cut-off value of CAR, and the median value was 0.095

Note: Weights are from random-effects analysis.

Abbreviations: $\mathrm{CAR}, \mathrm{C}$-reactive protein/albumin ratio; $\mathrm{HR}$, hazard ratio; $\mathrm{Cl}$, confidence interval.

this meta-analysis. However, Figure 6 shows that the results of most of the included studies are close to the central line without obvious deviation.

\section{Discussion}

A meta-analysis is a quantitative method of analyzing and integrating available studies on the same topic, which has evolved as an alternative to the conventional narrative review. ${ }^{38}$ A meta-analysis may help clinicians and researchers better understand the findings of clinical studies, draw conclusions about therapeutic effectiveness or plan new studies. ${ }^{39}$ When compared with any single study, meta-analysis results are more convincing, but sometimes, they can also be limited by sampling bias, inadequate data and interpretation of bias outcomes. ${ }^{40}$
Inflammation is a central aspect of the innate immune system response to tissue damage or infection. The relationship between inflammation and cancer has been recognized since 17 th century. ${ }^{4}$ Chronic inflammation can induce certain cancers and solid tumors (eg, hepatitis infection-related hepatocellular carcinoma, Helicobacter pylori infection-related gastric cancer and pancreatitis-related pancreatic carcinoma). Besides, inflammation is a critical component of tumor progression since tumor microenvironment could contribute to tumor invasion, migration and metastasis. ${ }^{41}$ Therefore, the relationship between cancer and inflammation has become the forefront of clinical oncology. ${ }^{42}$

$\mathrm{CRP}$ is a major component of any inflammatory reaction, which is generated from liver and belongs to pentraxin family. ${ }^{43}$ A systematic review with 271 articles demonstrated 


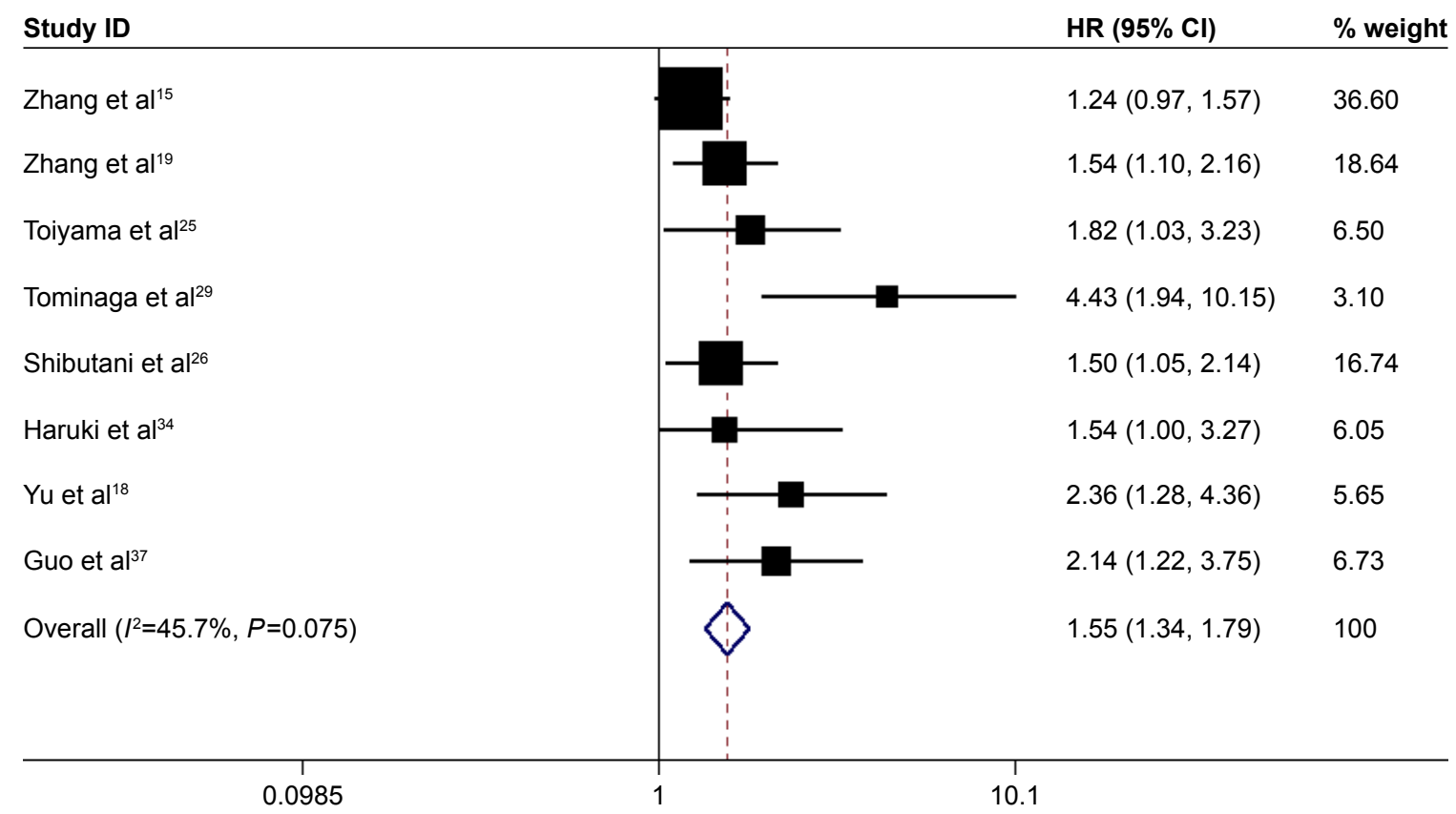

Figure 3 Forest plots for the prognostic impact of C-reactive protein/albumin ratio on disease-free survival in human malignancies. Abbreviations: $\mathrm{HR}$, hazard ratio; $\mathrm{Cl}$, confidence interval.

that high CRP was associated with higher mortality in $90 \%$ of reports on people with primary solid tumors, especially gastrointestinal malignancies and kidney malignancies. In addition, high CRP was correlated with poor treatment response and increased tumor recurrence. ${ }^{44}$

Human albumin (HA) is the most abundant plasma protein accounting for $\sim 50 \%$ of the total protein content. HA is a small globular protein with a molecular weight of $66.5 \mathrm{kDa}$, consisting of a single chain of 585 amino acids. ${ }^{45}$ As a major plasma protein, HA has been used for prognostic assessment in patients with different conditions, including hemodialysis patients, multiple myeloma patients and patients undergoing replacement albumin therapy. ${ }^{46}$ In addition, pretreatment serum protein is used as a prognostic marker in many human

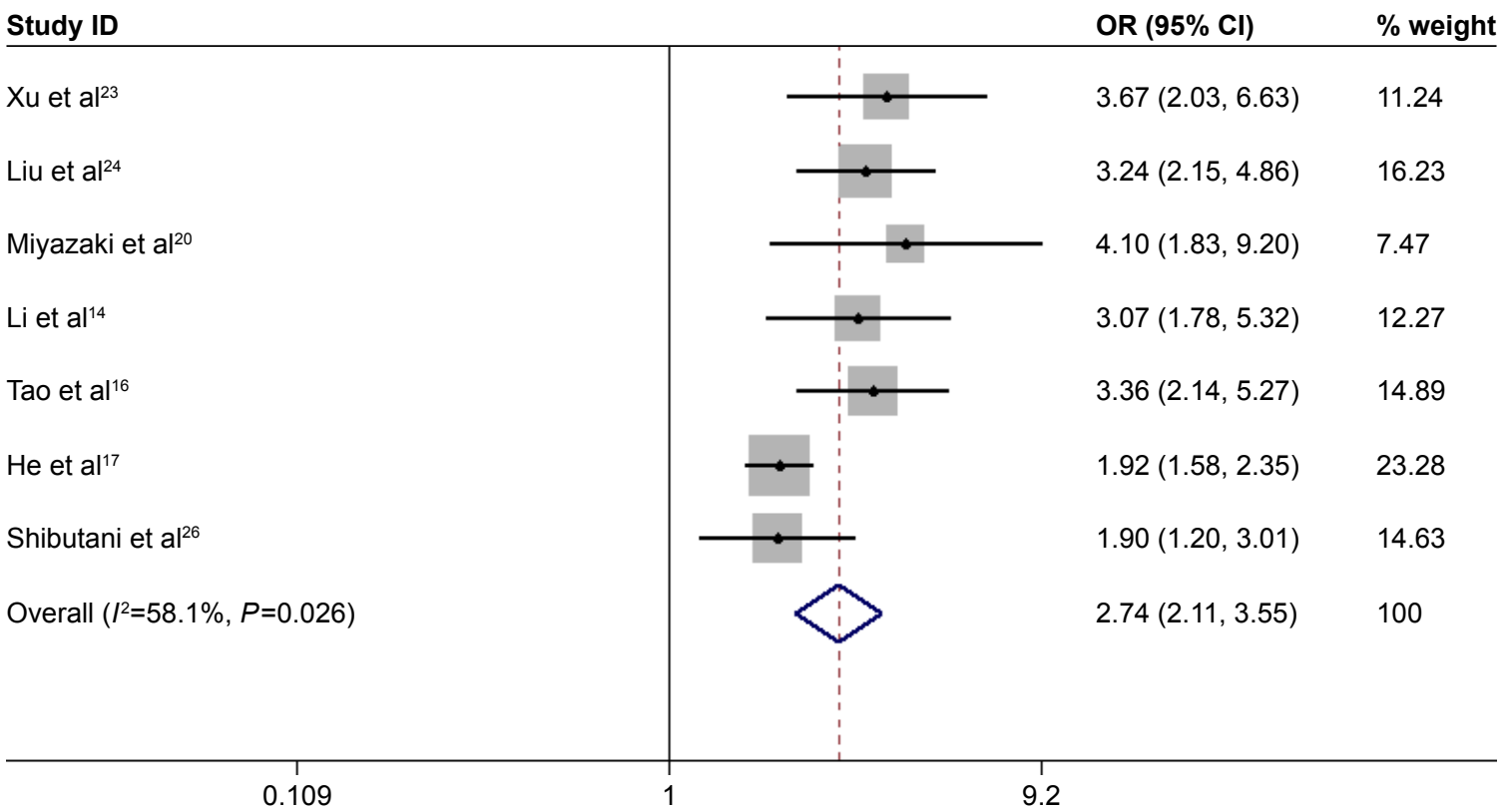

Figure 4 Forest plots for the prognostic impact of C-reactive protein/albumin ratio on 5-year mortality in human malignancies.

Note: Weights are from random-effects analysis.

Abbreviations: $\mathrm{OR}$, odds ratio; $\mathrm{Cl}$, confidence interval. 
Table 2 Subgroup analysis for the prognostic impact of C-reactive protein/albumin ratio on overall survival in human malignancies

\begin{tabular}{|c|c|c|c|c|c|c|}
\hline \multirow[t]{2}{*}{ Variables } & \multirow{2}{*}{$\begin{array}{l}\text { No of } \\
\text { studies }\end{array}$} & \multirow{2}{*}{$\begin{array}{l}\text { No of } \\
\text { patients }\end{array}$} & \multirow[t]{2}{*}{ HR (95\% Cl) } & \multirow[t]{2}{*}{$P$-value } & \multicolumn{2}{|c|}{ Heterogeneity } \\
\hline & & & & & $I^{2}(\%)$ & $P$-value \\
\hline Total & 25 & 12,097 & $1.99(1.65-2.40)$ & 0.000 & 86.9 & 0.000 \\
\hline \multicolumn{7}{|l|}{ Publication year } \\
\hline $2016-2017$ & 18 & 9,165 & $1.93(1.54-2.42)$ & 0.000 & 86.6 & 0.000 \\
\hline $2014-2015$ & 7 & 2,932 & $2.11(1.56-2.84)$ & 0.000 & 81.6 & 0.000 \\
\hline \multicolumn{7}{|l|}{ Country } \\
\hline China & 15 & 9,617 & $1.97(1.66-2.34)$ & 0.000 & 75.3 & 0.000 \\
\hline Others & 10 & 2,480 & $2.03(1.38-2.97)$ & 0.000 & 86.4 & 0.000 \\
\hline \multicolumn{7}{|l|}{ Sample size } \\
\hline$\geq 386$ & 14 & 10,426 & $1.91(1.64-2.24)$ & 0.000 & 63.5 & 0.001 \\
\hline$<386$ & II & $|, 67|$ & $2.10(1.45-3.04)$ & 0.000 & 90.6 & 0.000 \\
\hline \multicolumn{7}{|c|}{ Cut-off value for CAR } \\
\hline$>0.095$ & 12 & 4,146 & $2.00(1.47-2.72)$ & 0.000 & 92.7 & 0.000 \\
\hline$\leq 0.095$ & 13 & 7,951 & I.88 (1.57-2.25) & 0.000 & 51.5 & 0.016 \\
\hline \multicolumn{7}{|l|}{ Cancer sites } \\
\hline Nasopharynx & 4 & 5,385 & $1.56(1.25-1.94)$ & 0.000 & 35.8 & 0.197 \\
\hline Esophagus & 2 & 891 & $1.84(1.06-3.20)$ & 0.030 & 85.6 & 0.008 \\
\hline Lung & 3 & 1,092 & $1.63(1.24-2.15)$ & 0.046 & 45.4 & 0.160 \\
\hline Stomach & 2 & 839 & $1.73(1.31-2.28)$ & 0.000 & 0.0 & 0.388 \\
\hline Liver & 2 & 364 & $2.73(2.07-3.60)$ & 0.000 & 0.0 & 0.352 \\
\hline Pancreas & 4 & 814 & $2.25(1.52-3.34)$ & 0.000 & 69.8 & 0.019 \\
\hline Colorectum & 4 & 1,567 & $1.64(0.96-2.80)$ & 0.069 & 89.0 & 0.000 \\
\hline Kidney & 2 & 976 & $2.69(1.54-4.69)$ & 0.000 & 66.5 & 0.084 \\
\hline Others & 2 & 169 & $3.22(1.18-8.80)$ & 0.022 & 61.0 & 0.109 \\
\hline \multicolumn{7}{|l|}{ Treatments } \\
\hline Resection & 16 & 5,802 & $2.08(I .60-2.7 I)$ & 0.000 & 90.1 & 0.000 \\
\hline Others & 9 & 6,295 & I.82 (I.43-2.33) & 0.000 & 70.9 & 0.001 \\
\hline
\end{tabular}

Abbreviations: $\mathrm{HR}$, hazard ratio; $\mathrm{Cl}$, confidence interval; $\mathrm{CAR}, \mathrm{C}$-reactive protein/albumin ratio.

malignancies, including urinary carcinoma, ${ }^{47,48}$ head and neck cancer, ${ }^{49}$ lung cancer, ${ }^{50}$ gynecological cancer ${ }^{51,52}$ and gastrointestinal cancers. ${ }^{53,54}$

As a combined product, CAR, especially its prognostic role in human malignancies, was investigated by many studies recently. On January 27th 2017, Li et al published a meta-analysis, including only 10 studies with 4,592 cancer patients, investigating the prognostic role of CAR in human cancer. ${ }^{8}$ In their meta-analysis, the impact of pretreatment albumin-globulin ratio (AGR) on OS in human cancers was analyzed, but without DFS or 5-year mortality. As we all know, DFS and 5-year mortality rate are also considered as important indicators in the research on cancer prognosis. Moreover, the number of included studies and cancer patients was limited in this previously published paper. Therefore, we conducted this updated meta-analysis to investigate the prognostic value of pretreatment CAR in cancer patients. In this meta-analysis, we included 25 studies with 12,097 cases diagnosed with malignancy. The pooled results showed that high pretreatment CAR was associated with poor OS, poor DFS and high 5-year mortality, suggesting that pretreatment CAR might serve as a marker of poor survival rate and high tumor recurrence rate in human malignancies. Moreover, our subgroup meta-analysis showed that high pretreatment CAR was significantly associated with poor OS in patients with nasopharyngeal cancer, esophageal cancer, gastric cancer, liver cancer, pancreatic cancer, lung cancer, oral cancer and renal cancer, but not colorectal cancer. When compared with the previously published meta-analysis, our meta-analysis results are more reliable and convincing in addition to being based on more available studies.

However, this meta-analysis also has some limitations. Firstly, we did not perform methodological quality analysis for included studies, as no widely agreed quality criteria have been identified yet for assessing studies investigating prognosis. ${ }^{55}$ Secondly, heterogeneity was found in the meta-analysis with OS and 5-year mortality. We performed subgroup meta-analysis based on potential confounding factors including publication time, country, sample size, cut-off value for CAR and treatment, but heterogeneity could not be solved. However, when conducting subgroup meta-analysis based on cancer sites, no heterogeneity was 


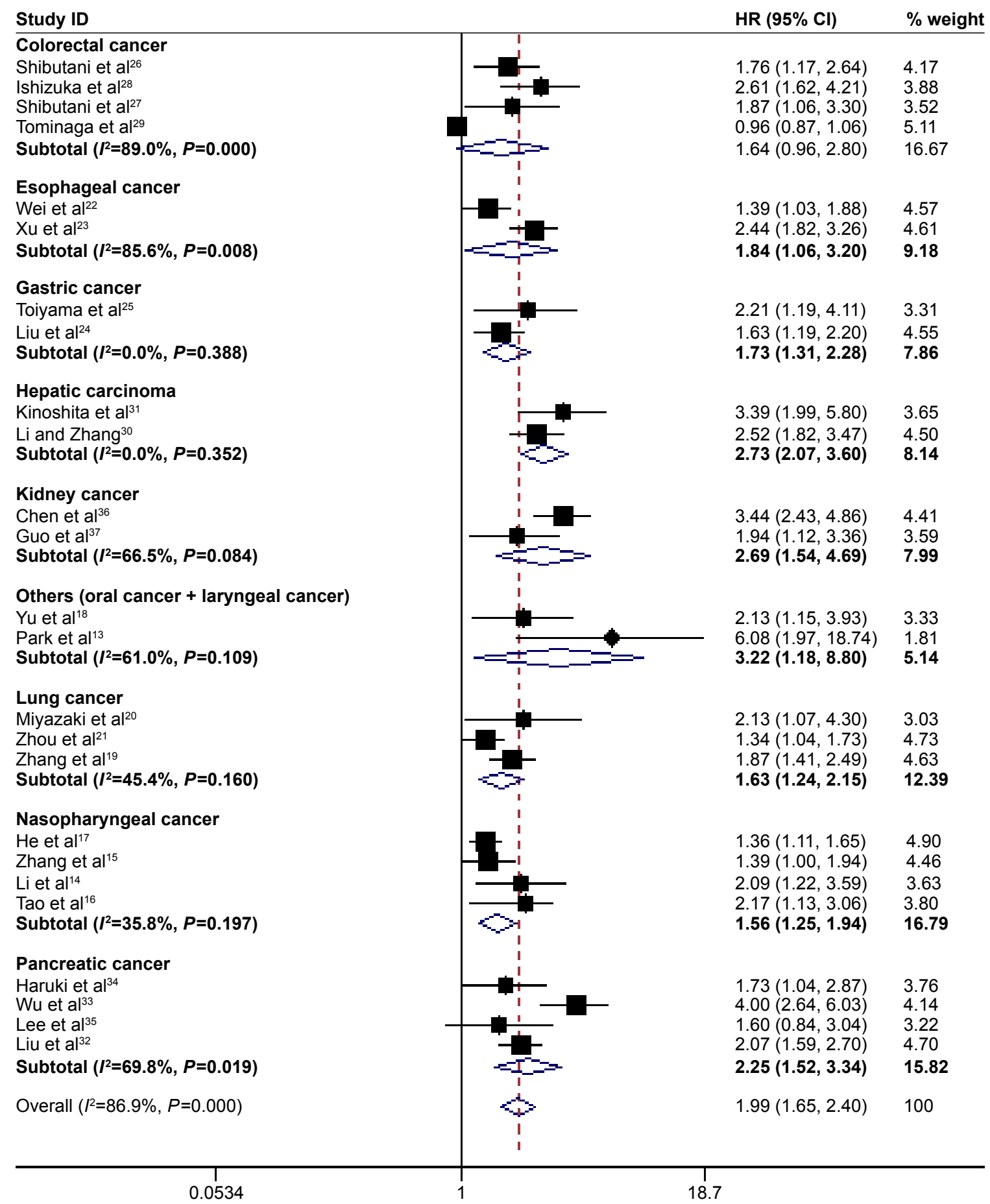

Figure 5 Forest plots for subgroup analysis based on the meta-analysis with overall survival according to different cancer types.

Note: Weights are from random-effects analysis.

Abbreviations: $\mathrm{HR}$, hazard ratio; $\mathrm{Cl}$, confidence interval.

found in the meta-analysis with nasopharyngeal cancer, lung cancer, gastric cancer or liver cancer. The other reason is that the cut-off values for CAR were highly diverse, which may also account for the heterogeneity to some extent. Last but not least, publication bias was found in the meta-analysis, which might have been caused by the following reasons.
Only articles in Chinese or English were included in this meta-analysis, though we did not set any language limitations during the searching process. In addition, some databases (eg, Embase database) were not available for our research group, and survival results were not provided or could not be calculated in some retracted articles. 


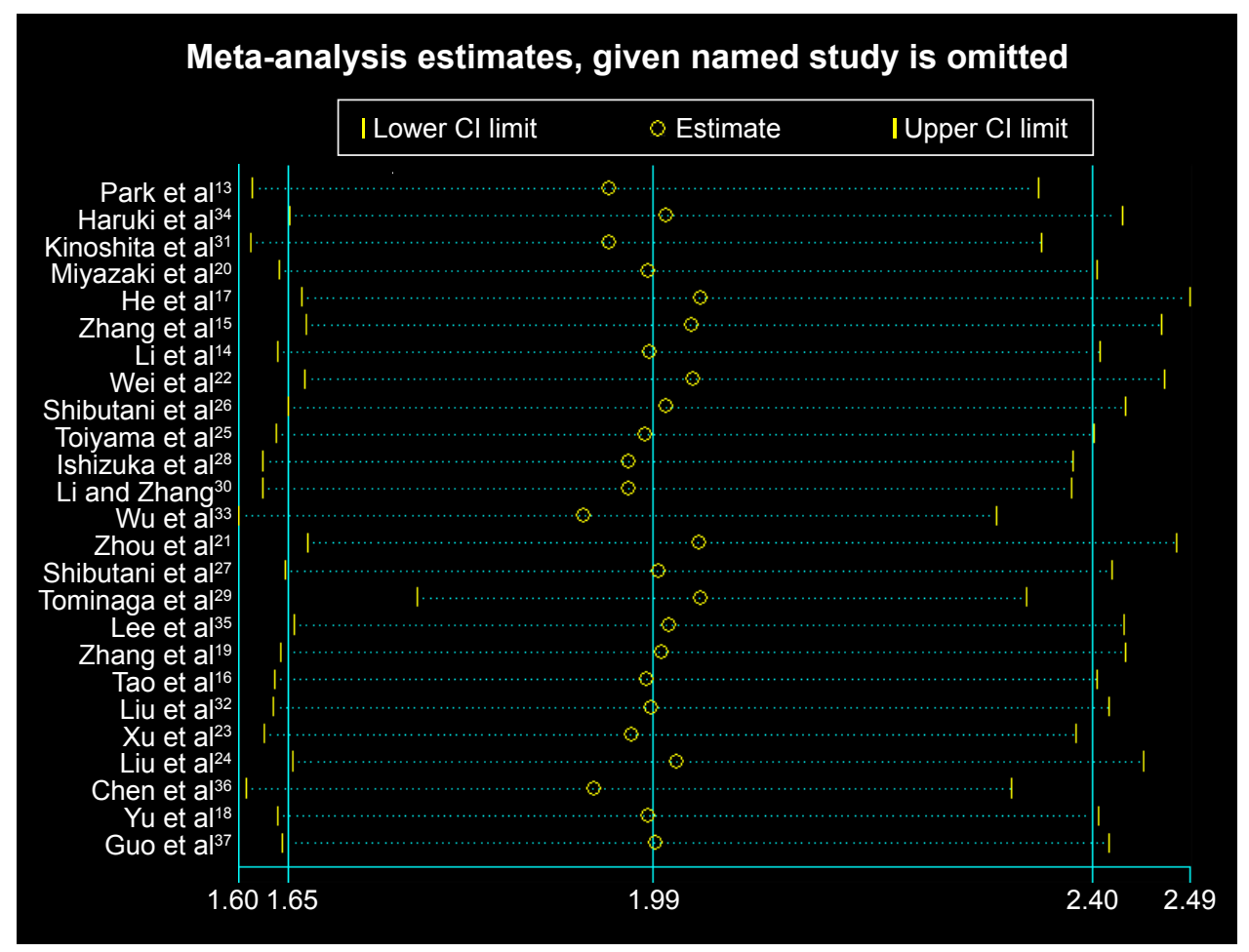

Figure 6 Sensitivity analysis for the studies included in the meta-analysis with overall survival in human malignancies. Abbreviation: $\mathrm{Cl}$, confidence interval.

At the same time, we also found other combined markers derived from albumin, such as albumin-bilirubin grade used for predicting prognosis in patients with hepatocellular carcinoma (HCC) $)^{56,57}$ and AGR used as a prognostic marker in patients with $\mathrm{HCC},{ }^{58}$ urinary carcinoma, ${ }^{59,60}$ lung cancer ${ }^{61}$ and endometrial cancer. ${ }^{51}$ Besides, we also found one study investigating the impact of CAR on long-term outcomes following hepatic resection for colorectal liver metastases. ${ }^{62}$ Thus, pretreatment CAR is a useful prognostic marker in cancer patients.

In summary, high pretreatment CAR was associated with poor OS, poor DFS and high 5-year mortality in human malignancies. Pretreatment CAR might serve as a marker of poor survival rate and high tumor recurrence rate in human malignancies except colorectal cancers. Therefore, CAR could be used in the evaluation of prognosis of human malignancies in clinical work. More prospective studies with large sample size are needed to explore the prognostic role of pretreatment CAR in patients with colorectal cancer.

\section{Acknowledgment}

The authors are grateful to Lin An (Department of Dermatology, China-Japan Union Hospital of Jilin University, Changchun, Jilin, China) for her help in this research.

\section{Disclosure}

The authors report no conflicts of interest in this work.

\section{References}

1. Siegel RL, Miller KD, Jemal A. Cancer statistics, 2017. CA Cancer J Clin. 2017;67(1):7-30.

2. Torre LA, Bray F, Siegel RL, Ferlay J, Lortet-Tieulent J, Jemal A. Global cancer statistics, 2012. CA Cancer J Clin. 2015;65(2):87-108.

3. Miller KD, Siegel RL, Lin CC, et al. Cancer treatment and survivorship statistics, 2016. CA Cancer J Clin. 2016;66(4):271-289.

4. Balkwill F, Mantovani A. Inflammation and cancer: back to Virchow? Lancet. 2001;357(9255):539-545.

5. McMillan DC. The systemic inflammation-based Glasgow Prognostic Score: a decade of experience in patients with cancer. Cancer Treat Rev. 2013;39(5):534-540.

6. Yodying H, Matsuda A, Miyashita M, et al. Prognostic significance of neutrophil-to-lymphocyte ratio and platelet-to-lymphocyte ratio in oncologic outcomes of esophageal cancer: a systematic review and meta-analysis. Ann Surg Oncol. 2016;23(2):646-654.

7. Nishijima TF, Muss HB, Shachar SS, Tamura K, Takamatsu Y. Prognostic value of lymphocyte-to-monocyte ratio in patients with solid tumors: a systematic review and meta-analysis. Cancer Treat Rev. 2015;41(10): 971-978.

8. Li N, Tian GW, Wang Y, Zhang H, Wang ZH, Li G. Prognostic role of the pretreatment $\mathrm{C}$-reactive protein/albumin ratio in solid cancers: a meta-analysis. Sci Rep. 2017;7:41298.

9. Tierney JF, Stewart LA, Ghersi D, Burdett S, Sydes MR. Practical methods for incorporating summary time-to-event data into meta-analysis. Trials. 2007;8:16.

10. Higgins JP, Thompson SG. Quantifying heterogeneity in a metaanalysis. Stat Med. 2002;21(11):1539-1558.

11. Begg CB, Mazumdar M. Operating characteristics of a rank correlation test for publication bias. Biometrics. 1994;50(4):1088-1101. 
12. Egger M, Davey Smith G, Schneider M, Minder C. Bias in meta-analysis detected by a simple, graphical test. BMJ. 1997;315(7109):629-634.

13. Park HC, Kim MY, Kim CH. C-reactive protein/albumin ratio as prognostic score in oral squamous cell carcinoma. J Korean Assoc Oral Maxillofac Surg. 2016;42(5):243-250.

14. Li JP, Chen SL, Liu XM, et al. A novel inflammation-based stage (I stage) predicts overall survival of patients with nasopharyngeal carcinoma. Int J Mol Sci. 2016;17(11).

15. Zhang Y, Zhou GQ, Liu X, et al. Exploration and validation of C-reactive protein/albumin ratio as a novel inflammation-based prognostic marker in nasopharyngeal carcinoma. J Cancer. 2016;7(11): 1406-1412.

16. Tao CJ, Chen YY, Jiang F, et al. The C-reactive protein/albumin ratio is an independent prognostic factor for overall survival in patients with nasopharyngeal carcinoma receiving intensity-modulated radiotherapy. J Cancer. 2016;7(14):2005-2011.

17. He S, Wang Y, Chen $\mathrm{H}$, et al. C-reactive protein/albumin ratio (CAR) as a prognostic factor in patients with non-metastatic nasopharyngeal carcinoma. J Cancer. 2016;7(15):2360-2366.

18. Yu ST, Zhou Z, Cai Q, et al. Prognostic value of the C-reactive protein/ albumin ratio in patients with laryngeal squamous cell carcinoma. Onco Targets Ther. 2017;10:879-884

19. Zhang F, Ying L, Jin J, et al. The C-reactive protein/albumin ratio predicts long-term outcomes of patients with operable non-small cell lung cancer. Oncotarget. 2017;8(5):8835-8842.

20. Miyazaki T, Yamasaki N, Tsuchiya T, et al. Ratio of C-reactive protein to albumin is a prognostic factor for operable non-small-cell lung cancer in elderly patients. Surg Today. Epub 2016 Nov 16.

21. Zhou T, Zhan J, Hong S, et al. Ratio of C-reactive protein/albumin is an inflammatory prognostic score for predicting overall survival of patients with small-cell lung cancer. Sci Rep. 2015;5:10481.

22. Wei XL, Wang FH, Zhang DS, et al. A novel inflammation-based prognostic score in esophageal squamous cell carcinoma: the $\mathrm{C}$-reactive protein/albumin ratio. BMC Cancer. 2015;15:350.

23. Xu XL, Yu HQ, Hu W, et al. A novel inflammation-based prognostic score, the C-reactive protein/albumin ratio predicts the prognosis of patients with operable esophageal squamous cell carcinoma. PLoS One. 2015;10(9):e0138657.

24. Liu X, Sun X, Liu J, et al. Preoperative C-reactive protein/albumin ratio predicts prognosis of patients after curative resection for gastric cancer. Transl Oncol. 2015;8(4):339-345.

25. Toiyama Y, Shimura T, Yasuda H, et al. Clinical burden of C-reactive protein/albumin ratio before curative surgery for patients with gastric cancer. Anticancer Res. 2016;36(12):6491-6498.

26. Shibutani M, Maeda K, Nagahara H, Iseki Y, Hirakawa K, Ohira M. The significance of the $\mathrm{C}$-reactive protein to albumin ratio as a marker for predicting survival and monitoring chemotherapeutic effectiveness in patients with unresectable metastatic colorectal cancer. Springerplus. 2016;5(1): 1798 .

27. Shibutani M, Maeda K, Nagahara H, Iseki Y, Ikeya T, Hirakawa $\mathrm{K}$. Prognostic significance of the preoperative ratio of C-reactive protein to albumin in patients with colorectal cancer. Anticancer Res. 2016; 36(3):995-1001.

28. Ishizuka M, Nagata H, Takagi K, Iwasaki Y, Shibuya N, Kubota K. Clinical significance of the $\mathrm{C}$-reactive protein to albumin ratio for survival after surgery for colorectal cancer. Ann Surg Oncol. 2016;23(3): 900-907.

29. Tominaga T, Nonaka T, Sumida Y, Hidaka S, Sawai T, Nagayasu T. The C-reactive protein to albumin ratio as a predictor of severe side effects of adjuvant chemotherapy in stage III colorectal cancer patients. PLoS One. 2016;11(12): 0167967.

30. Li M, Zhang P. [Predictive value of C-reactive protein/albumin ratio on prognosis of patients with primary hepatocellular carcinoma]. Cancer Res Prev Treat. 2016;43(7):598-601. Chinese.

31. Kinoshita A, Onoda H, Imai N, et al. The C-reactive protein/albumin ratio, a novel inflammation-based prognostic score, predicts outcomes in patients with hepatocellular carcinoma. Ann Surg Oncol. 2015; 22(3):803-810.
32. Liu Z, Jin K, Guo M, et al. Prognostic value of the CRP/Alb ratio, a novel inflammation-based score in pancreatic cancer. Ann Surg Oncol. 2017;24(2):561-568.

33. Wu M, Guo J, Guo L, Zuo Q. The C-reactive protein/albumin ratio predicts overall survival of patients with advanced pancreatic cancer. Tumour Biol. 2016;37(9):12525-12533.

34. Haruki K, Shiba H, Shirai Y, et al. The C-reactive protein to albumin ratio predicts long-term outcomes in patients with pancreatic cancer after pancreatic resection. World J Surg. 2016;40(9):2254-2260.

35. Lee JM, Lee HS, Hyun JJ, et al. Prognostic value of inflammation-based markers in patients with pancreatic cancer administered gemcitabine and erlotinib. World J Gastrointest Oncol. 2016;8(7):555-562.

36. Chen Z, Shao Y, Fan M, et al. Prognostic significance of preoperative C-reactive protein: albumin ratio in patients with clear cell renal cell carcinoma. Int J Clin Exp Pathol. 2015;8(11):14893-14900.

37. Guo S, He X, Chen Q, et al. The C-reactive protein/albumin ratio, a validated prognostic score, predicts outcome of surgical renal cell carcinoma patients. BMC Cancer. 2017;17(1):171.

38. Katerndahl DA, Cohen PA. Quantitatively reviewing the literature: the application of meta-analysis. Fam Pract Res J. 1987;6(3):123-129.

39. L'Abbé KA, Detsky AS, O'Rourke K. Meta-analysis in clinical research. Ann Intern Med. 1987;107(2):224-233.

40. Thacker SB. Meta-analysis. A quantitative approach to research integration. JAMA. 1988;259(11):1685-1689.

41. Coussens LM, Werb Z. Inflammation and cancer. Nature. 2002; 420(6917):860-867.

42. Munn LL. Cancer and inflammation. Wiley Interdiscip Rev Syst Biol Med. 2017;9(2). Epub 2016 Dec 12.

43. Ansar W, Ghosh S. C-reactive protein and the biology of disease. Immunol Res. 2013;56(1):131-142.

44. Shrotriya S, Walsh D, Bennani-Baiti N, Thomas S, Lorton C. C-reactive protein is an important biomarker for prognosis tumor recurrence and treatment response in adult solid tumors: a systematic review. PLoS One. 2015;10(12):e0143080.

45. Caraceni P, Tufoni M, Bonavita ME. Clinical use of albumin. Blood Transfus. 2013;11 Suppl 4:s18-s25.

46. Infusino I, Panteghini M. Serum albumin: accuracy and clinical use. Clin Chim Acta. 2013;419:15-18.

47. Chen Z, Shao Y, Wang K, et al. Prognostic role of pretreatment serum albumin in renal cell carcinoma: a systematic review and meta-analysis. Onco Targets Ther. 2016;9:6701-6710.

48. Ku JH, Kim M, Choi WS, Kwak C, Kim HH. Preoperative serum albumin as a prognostic factor in patients with upper urinary tract urothelial carcinoma. Int Braz J Urol. 2014;40(6):753-762.

49. Danan D, Shonka DC Jr, Selman Y, Chow Z, Smolkin ME, Jameson MJ. Prognostic value of albumin in patients with head and neck cancer. Laryngoscope. 2016;126(7):1567-1571.

50. Espinosa E, Feliu J, Zamora P, et al. Serum albumin and other prognostic factors related to response and survival in patients with advanced nonsmall cell lung cancer. Lung Cancer. 1995;12(1-2):67-76.

51. Seebacher V, Grimm C, Reinthaller A, et al. The value of serum albumin as a novel independent marker for prognosis in patients with endometrial cancer. Eur J Obstet Gynecol Reprod Biol. 2013;171(1):101-106.

52. Asher V, Lee J, Bali A. Preoperative serum albumin is an independent prognostic predictor of survival in ovarian cancer. Med Oncol. 2012;29(3):2005-2009.

53. Lien YC, Hsieh CC, Wu YC, et al. Preoperative serum albumin level is a prognostic indicator for adenocarcinoma of the gastric cardia. J Gastrointest Surg. 2004;8(8):1041-1048.

54. Heys SD, Walker LG, Deehan DJ, Eremin OE. Serum albumin: a prognostic indicator in patients with colorectal cancer. $J R$ Coll Surg Edinb. 1998;43(3):163-168.

55. Altman DG. Systematic reviews of evaluations of prognostic variables. BMJ. 2001;323(7306):224-228.

56. Ma XL, Zhou JY, Gao XH, et al. Application of the albuminbilirubin grade for predicting prognosis after curative resection of patients with early-stage hepatocellular carcinoma. Clin Chim Acta. 2016;462:15-22. 
57. Li MX, Zhao H, Bi XY, et al. Prognostic value of the albumin-bilirubin grade in patients with hepatocellular carcinoma: validation in a Chinese cohort. Hepatol Res. Epub 2016 Aug 25.

58. Zhang J, Liu X, Yang Z, Chen Y, Luo R. The pretreatment albumin to globulin ratio, a validated biomarker, predicts prognosis in hepatocellular carcinoma. J BUON. 2016;21(4):925-934.

59. Zhang B, Yu W, Zhou LQ, et al. Prognostic significance of preoperative albumin-globulin ratio in patients with upper tract urothelial carcinoma. PLoS One. 2015;10(12):e0144961.

60. Liu J, Dai Y, Zhou F, et al. The prognostic role of preoperative serum albumin/globulin ratio in patients with bladder urothelial carcinoma undergoing radical cystectomy. Urol Oncol. 2016;34(11): 484.e1-484.e8.
61. Zhou T, He X, Fang W, et al. Pretreatment albumin/globulin ratio predicts the prognosis for small-cell lung cancer. Medicine (Baltimore). 2016;95(12):e3097.

62. Haruki K, Shiba H, Horiuchi T, et al. Impact of the C-reactive protein to albumin ratio on long-term outcomes after hepatic resection for colorectal liver metastases. Am J Surg. Epub 2017 Feb 6.

\section{Publish your work in this journal}

OncoTargets and Therapy is an international, peer-reviewed, open access journal focusing on the pathological basis of all cancers, potential targets for therapy and treatment protocols employed to improve the management of cancer patients. The journal also focuses on the impact of management programs and new therapeutic agents and protocols on

\section{Dovepress}

patient perspectives such as quality of life, adherence and satisfaction. The manuscript management system is completely online and includes a very quick and fair peer-review system, which is all easy to use. Visit http://www.dovepress.com/testimonials.php to read real quotes from published authors. 